\title{
Quantitative study of ageing changes in the human sinoatrial node and internodal tracts
}

\author{
M. J. Davies and Ariela Pomerance \\ From St. George's Hospital and Central Middlesex Hospital, London
}

Quantitative analysis of the amount of muscle, fat, and collagen in the human sinoatrial node and internodal tracts has been carried out. Subjects under 50 were compared with those over 75 years of age at death. In old age there is a significant fall in the amount of muscle present in the sinoatrial node and internodal tracts.

It has long been accepted that the sinoatrial node is the normal pacemaker of the heart. More recently it has been established that specialized atrial myogenic conduction paths carry the impulse to the atrioventricular node (James, 1963; Merideth and Titus, 1968); it is now universally accepted that the automaticity of the sinoatrial node is a function of cardiac muscle fibres. Elderly subjects seem particularly prone to develop atrial arrhythmias (Taran and Szilagyi, 1958), and ageing changes in the sinoatrial node and internodal tracts may be a factor accounting for this phenomenon. However, the very existence of such ageing changes is debated; Lev did note (1954) and has illustrated (1968) fibrosis in the sinoatrial nodes of elderly subjects but these findings were not confirmed by Rossi (I969). The present study is designed to resolve this point on a quantitative basis.

\section{Materials and methods}

The hearts of 50 subjects under 50 years of age were compared with 50 hearts from subjects over 75 years of age at death; the minimum age was 37 years and the maximum 89 years. Hearts were taken only from subjects with no history of arrhythmias and sinus rhythm recorded within one week of death. No case is included with an isolated right ventricular weight above $60 \mathrm{~g}$ or an isolated left ventricular weight above $200 \mathrm{~g}$. In all cases postmortem coronary angiography was performed with simultaneous injection into both coronary arteries of a gelatin-barium suspension at $80 \mathrm{mmHg}$ pressure for ro minutes. No case showing any area of coronary stenosis greater than 20 per cent is included. There was rigid exclusion of any heart showing evidence of old or recent infarction, any form of valve disease, or of any other recognizable pathological process. The

Received 22 March 197 I. principal causes of death were malignancy including many cerebral tumours, trauma, drug overdose, and bronchopneumonia.

The entire sinoatrial ring was excised, opened posteriorly, and pinned flat for fixation. Subsequently the entire ring was divided into blocks, one or more of which contained the sinoatrial node, for examination by subserial section (Hudson, 1965; Davies, 1971). Serial blocks were taken of the three main internodal tracts, anterior, middle, and posterior, down to immediately above the atrioventricular node. In practice, therefore, the entire sinoatrial ring, interatrial septum, and posterior wall of the right atrium was blocked.

Cavity size of the right and left atria was determined by filling them with molten paraffin wax. The weights of the solid casts of the atria were subsequently used to calculate volumes. In order to eliminate variation due to fixation shrinkage every heart was fixed for between 5 and 7 days in 4 per cent formaldehyde in saline.

Histological slides were stained routinely by haematoxylin and eosin, elastic van Gieson, and a modification of the picro-Mallory stain.

Identification of the sinoatrial node by naked eye is easily made in the slides stained by the picro-Mallory technique because of its collagen content, and its outline was marked on the cover glass in Indian ink. Subsequently the ratio of collagen (blue staining) to muscle (red staining) was calculated within this circle using a Zeiss I integrating eyepiece (Dunnill, 1962). In all, 8 to I2 slides evenly distributed through the node were so assessed. The figures were used to calculate the percentages of collagen and muscle in the node. Vessel walls and their lumen were not counted. The ratio of collagen to muscle and fat throughout the internodal tracts was calculated in a similar manner. Slides evenly distributed throughout the tracts were assessed to obtain an overall figure for the ratio of collagen to muscle and to fat.

The nodal artery was measured using a Zeiss graduated eyepiece; the ratio of lumen to intimal 
and medial thickness was determined in arbitrary units. Where more than one nodal artery was present, the largest was measured. With the technique of examination used, the nodal artery is invariably cut in exact transverse section, and measurement in only one plane is necessary.

The results were analysed by use of the Student ' $t$ ' test since distribution approximated to normal. Results were considered significant at the $\mathbf{P}<0.05$ level.

\section{Results}

In essence the sinoatrial node is a crescentic mass of muscle fibres, arranged in a complex branching network, embedded in a fibroelastic matrix. A central artery runs through the long axis of the node and gives rise to numerous smaller branches which run in parallel. In some instances (10\%) this division takes place outside the node and there is no single main nodal artery. The nodal artery is the termination of the main atrial artery and is derived either from the proximal portion of the right coronary artery $(59 \%)$ or from the left circumflex coronary artery $(36 \%)$. Less commonly, branches from both right coronary artery and the left circumflex artery join to form a circle round the sinoatrial ring ( $5 \%$ ).

Comparison of the sinoatrial node in the two age groups shows a clear and significant fall in the percentage of muscle in the older age range (Table and Fig.). This is associated with a corresponding increase in the percentage of fibrous tissue. No increase of adipose tissue within the node itself was found. In no instance was more than 5 per cent of the node occupied by fat cells in either age group.

TABLE

\begin{tabular}{|c|c|c|}
\hline & $\begin{array}{l}<50 \text { years } \\
\text { of age }\end{array}$ & $\begin{array}{l}>75 \text { years } \\
\text { of age }\end{array}$ \\
\hline \multicolumn{3}{|l|}{ Right atrial volume } \\
\hline $\begin{array}{l}\text { Mean } \\
\text { SD } \\
\text { Range }\end{array}$ & $\begin{array}{c}39.2 \mathrm{ml} \\
2.8\end{array}$ & $\begin{array}{c}46.8 \mathrm{ml} \\
5.1\end{array}$ \\
\hline \multicolumn{3}{|l|}{ Left atrial volume } \\
\hline $\begin{array}{l}\text { Mean } \\
\text { SD } \\
\text { Range }\end{array}$ & $\begin{array}{c}37 \mathrm{ml} \\
3.0\end{array}$ & $\begin{array}{c}49 \mathrm{ml} \\
6.9\end{array}$ \\
\hline \multicolumn{3}{|c|}{ Per cent muscle in sinoatrial node* } \\
\hline Mean & $46 \%$ & $27 \%$ \\
\hline SD & 4.4 & $6 \cdot 2$ \\
\hline Range & $35-58 \%$ & $I I-4 I \%$ \\
\hline \multicolumn{3}{|c|}{ Per cent fibrosis in internodal tracts } \\
\hline Mean & I6.7\% & $36 \%$ \\
\hline $\begin{array}{l}\text { SD } \\
\text { Range }\end{array}$ & $\begin{array}{l}4.5 \\
8-20 \%\end{array}$ & $\begin{array}{l}5.7 \\
24-52 \%\end{array}$ \\
\hline \multicolumn{3}{|c|}{ Per cent fat in internodal tracts } \\
\hline Mean & $14 \cdot 8 \%$ & $19 \cdot 3 \%$ \\
\hline SD & $7 \cdot 7$ & 8.7 \\
\hline
\end{tabular}

$\star P<0.05$

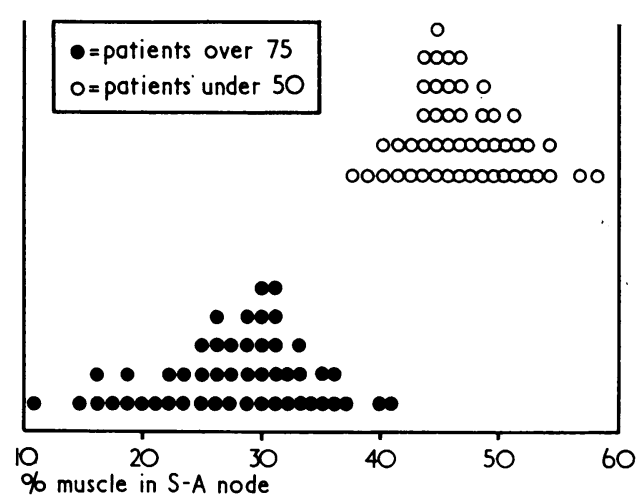

FIG. Comparison of the per cent muscle in the sinoatrial node in young and old subjects.

The mean values in arbitrary units for the thickness of intima and media and diameter of lumen in the nodal artery were $2 \cdot 6$, 6.6 , and 29 in subjects under 50 years of age and $2 \cdot 0,5 \cdot 5$, and 51 for subjects over 75 . The mean ratio of intimal to medial thickness was $I$ to 2.5 in subjects under 50 and $I$ to 2.7 in the older group. The mean diameter of the lumen was therefore considerably increased ( 29 to 5I) in the elderly subjects.

The percentage of fibrosis in the internodal tracts increases significantly with age. Both young and old subjects show a wide scatter in the amount of fat present in the internodal tracts and there was no significant change with age.

The volume of both atria increases with age and shows a wider scatter in the older age group as compared with younger subjects (Table) but the difference does not reach significance at the 0.05 level. All of the parameters measured alter with age but there remains some overlap in the two age groups. The loss of muscle and increase in collagen in the sinoatrial node are the most significant changes (Fig.).

\section{Discussion}

Our findings related to the overall morphology of the sinoatrial node and its vasculature conform to those previously described (Hudson, 1965; Verhaeghe and van der Hauwaert, 1967). The origin of the nodal artery in this series is not greatly different from the figures reported by Romhilt, Hackel, and Estes (I968).

There is appreciable muscle fibre loss in the sinoatrial node of clinically normal people with age, and similar but less pronounced changes occur in the internodal tracts. This finding is in accord with Lev's (1968) work but in direct opposition to that of Rossi 
(1969). It is very unlikely that the muscle fibre loss is related to either large or small coronary artery disease. Rigid selection of the material excludes coronary atherosclerosis as a factor and the lumen of the nodal artery itself is larger in old age, the senile ectasia probably being a reflection of atrophy of the media. Muscle loss is accompanied by an increase in fibrous tissue in both the sinoatrial node and the internodal tracts. Fatty infiltration has been implicated as an ageing change (Balsaver, Morales, and Whitehouse, 1967) but in the present series there was little support for this view. There is great variation in the amount of adipose tissue in the tracts but not in the node in both age groups. A degree of dilatation occurs with age in both atria, the reasons for which are obscure; it may be simply a consequence of muscle atrophy. Left atrial dilatation could result from minor degrees of mitral incompetence due to senile ring calcification or mucoid change in the valve cusps, but it must be borne in mind that cases with these changes recognizable macroscopically were excluded.

All the hearts in this series were rigidly selected for macroscopical normality. Hearts with obvious pathological changes presumably could show, depending on the nature of the pathology, accentuation of loss of muscle fibres in the sinoatrial node and internodal tracts. The two age groups were selected to reflect the extremes of any age-related changes and the investigation was so designed to provide control data for a study of atrial fibrillation in old age (to be published). The results of this study are probably influenced by the unavoidable selection factors associated with hospital admissions. The patients in the younger age group were active until shortly before death, in contrast with the majority of those in the older group who had spent some weeks in bed before death. We have no data on heart changes in the absolutely fit, active octogenarian who has never been admitted to hospital. While much more quantitative data at all ages would be necessary for certainty, it is our strong impression that muscle loss and increase of fibrosis in the atria is a slow but continuous process starting around 60 years of age.

Atrial arrhythmias have many predisposing factors and not all cases are the result of recognizable morphological damage. Pathological processes recognized in hearts from patients with atrial fibrillation include fibrosis of the sinoatrial node (Hudson, 1960), dilatation of the atria (Laas, 1962), and damage to atrial muscle (James, 1962). Since all these features are already present in old age, the changes could well account for the ease with which atrial arrhythmias can be induced in old age.

\section{References}

Balsaver, A. M., Morales, A. R., and Whitehouse, F. W. (1967). Fat infiltration of the myocardium as a cause of cardiac conduction defect. American fournal of Cardiology, 19, 26r.

Davies, M. J. (197I). The Pathology of the Conduction System of the Heart. Butterworth, London.

Dunnill, M. S. (1962). Quantitative methods in the study of pulmonary pathology. Thorax, 17, 320 .

Hudson, R. E. B. (1960). The human pacemaker and its pathology. British Heart fournal, 22, 153.

Hudson, R. E. B. (1965). Cardiovascular Pathology, Vol. I. E. Arnold, London.

James, T. N. (1962). Arrhythmias and conduction disturbances in acute myocardial infarction. American Heart fournal, 64, 416.

James, T. N. (1963). The connecting pathways between the sinus node and A-V node and between the right and the left atrium in the human heart. American Heart fournal, 66, 498.

Laas, E. (1962). Das Arrhythmieherz. Zentralblatt für allgemeine Pathologie und pathologische Anatomie, ro3, 552.

Lev, M. (1954). Aging changes in the human sinoatrial node. Fournal of Gerontology, 9, I.

Lev, M. (1968). The conduction system. In Pathology of the Heart and Blood Vessels, 3rd ed., p. 182. Ed. by S. E. Gould. C. C. Thomas, Springfield, Illinois.

Merideth, J., and Titus, J. L. (1968). The anatomic atrial connections between sinus and $\mathrm{A}-\mathrm{V}$ node. Circulation, 37, 566.

Romhilt, D. W., Hackel, D. B., and Estes, E. H. (1968). Origin of blood supply to sinoauricular and atrioventricular node. American Heart fournal, 75, 279.

Rossi, L. (1969). Histopathological Features of Cardiac Arrhythmias. Casa Editace Ambrosiana, Milan.

Taran, L. M., and Szilagyi, N. (1958). Electrocardiographic changes with advancing age. Geriatrics, 13, 352.

Verhaeghe, L., and van der Hauwaert, L. (1967). Arterial blood supply of the human sinus node. British Heart fournal, 29, 80I.

Requests for reprints to Dr. M. J. Davies, Department of Histopathology, St. George's Hospital Medical School, Hyde Park Corner, London S.W.I. 